\title{
On Common Coupled Fixed Point Theorems for Comparable Mappings in Ordered Partially Metric Spaces
}

\author{
Ali Mutlu, ${ }^{1}$ Nermin Yolcu, ${ }^{1}$ Berrin Mutlu, ${ }^{2}$ and Necdet Bildik ${ }^{1}$ \\ ${ }^{1}$ Department of Mathematics, Faculty of Science and Arts, Celal Bayar University Muradiye Campus, 45047 Manisa, Turkey \\ ${ }^{2}$ Hasan Türek Anatolian High School, 45200 Manisa, Turkey
}

Correspondence should be addressed to Ali Mutlu; ali.mutlu@cbu.edu.tr

Received 13 September 2013; Accepted 31 October 2013; Published 29 January 2014

Academic Editor: Abdon Atangana

Copyright (C) 2014 Ali Mutlu et al. This is an open access article distributed under the Creative Commons Attribution License, which permits unrestricted use, distribution, and reproduction in any medium, provided the original work is properly cited.

Common coupled fixed point theorems are examined in this paper for comparable mappings ensuring nonlinear contraction in ordered partial metric spaces. Given theorems enlarge and universalize some conclusions of Gnana Bhaskar and Lakshmikantham (2006).

\section{Introduction}

The contraction method presented the fixed point theory on partially metric spaces. It is enlarged to nonlinear contraction mapping, which is attributed by many authors. (cf. [1-25]). Particularly a partial metric space is a universalized metric space. Some further generalizations of the conclusions in [16] are demonstrated by Valero [25], Oltra and Valero [18], Shatanawi et al. [23], and Altun and Erduran [5]. Additionally, Caristi type fixed point theorem on a partial metric space was introduced by Romaguera [21].

Existence of fixed points was introduced in ordered metric spaces by Ran and Reurings [19]. Some applications of fixed points are also shown for linear and nonlinear equations. Fixed and common fixed point theorems are searched recently by many authors on this topic. Moreover coupled coincidence and coupled fixed point theorems for two mappings $F$ and $g$ such that $F$ has to be mixed gmonotone property are stated by Lakshmikantham and Ćirić [15].

The authors propose to give more information about couple fixed point theory exists in the theory [1-25] for the reader.

Let us give some necessarily definitions related to mixed monotone maps and common coupled fixed point of a mapping.
Definition 1. Suppose that $(X, \leq)$ is a partially ordered set and also $F: X \times X \rightarrow X$. Assume that $F(x, y)$ is monotone nondecreasing pursuant $x$ and also is monotone nonincreasing according to $y$, for any $x, y \in X$, at the time the map $F$ is named to have mixed monotone property:

$$
\begin{gathered}
x_{1}, x_{2} \in X, x_{1} \leq x_{2} \text { implies } F\left(x_{1}, y\right) \leq F\left(x_{2}, y\right), \\
y_{1}, y_{2} \in X, y_{1} \leq y_{2} \text { implies } F\left(x, y_{1}\right) \geq F\left(x, y_{2}\right) \text { (see [15]). }
\end{gathered}
$$

Definition 2. If $F(y, x)=y$ and $F(x, y)=x$, then $(x, y) \in$ $X \times X$ is defined as an a coupled fixed point of a mapping $F: X \times X \rightarrow X[15]$.

Definition 3. Suppose that $X$ is a nonempty set. A partial metric on $X$ is a real function of $d$ of ordered pairs of elements of $X$ which satisfies the following four conditions:

$\left(\mathrm{pms}_{1}\right) x=y \Leftrightarrow d(x, x)=d(x, y)=d(y, y)$,

$\left(\mathrm{pms}_{2}\right) d(x, x) \leq d(x, y)$,

$\left(\mathrm{pms}_{3}\right) d(x, y)=d(y, x)$,

$\left(\mathrm{pms}_{4}\right) d(x, y) \leq d(x, z)+d(z, y)-d(z, z)[16]$.

A metric space consists of two objects: a set $X \neq \emptyset$ and partial metric $d$ on $X$, and also the elements of $X$ are called the point of the metric space $(X, d)$ (see $[16])$. 
Notice that the span of any point to itself need not be null; so universalizing metrics, namely, a metric on a set $X \neq \emptyset$, are named to be a partial metric $d$ on $X$ providing $d(x, x)=0$ for any $x \in X$. We refer the reader to check some results and related examples on partial metric spaces in the theory [1-25].

Each partial metric $d$ on $X$ generates a $T_{0}$ topology $\tau_{p}$ on $X$, which has a base of the family of open p-balls $\left\{B_{p}(x, \varepsilon), x \in\right.$ $X, \varepsilon>0\}$, where

$$
B_{p}(x, \varepsilon)=\{\gamma \in X: d(x, y)<d(x, x)+\varepsilon\} .
$$

If $d$ is a partial metric on $X$, then the function $d^{s}: X \times$ $X \rightarrow \mathbb{R}^{+}$given by

$$
d^{s}(x, y)=2 d(x, y)-d(x, x)-d(y, y)
$$

is a metric on $X$.

Definition 4. Assume that $(X, d)$ is a partial metric space and also $\left\{x_{n}\right\}$ is a sequence in $X$.

At the time,

(i) $d(x, x)=\lim _{n \rightarrow \infty} d\left(x_{n}, x\right) \Leftrightarrow\left\{x_{n}\right\}$ converges to a point $x \in X$,

(ii) if there exists $\lim _{n, m \rightarrow \infty} d\left(x_{n}, x_{m}\right)$, then $\left\{x_{n}\right\}$ is a Cauchy sequence [5].

Definition 5. A partial metric space $(X, d)$ is named to be complete if every Cauchy sequence $\left\{x_{n}\right\}$ in $X$ converges,

in accordance with $\tau_{p}$, to a point $x \in X$, with $d(x, x)=$ $\lim _{n, m \rightarrow \infty} d\left(x_{n}, x_{m}\right)[5]$.

Lemma 6. Suppose that $(X, d)$ is a partial metric space. At the time

(i) the sequence $\left\{x_{n}\right\}$ is Cauchy sequence in $(X, d) \Leftrightarrow$ it is a Cauchy sequence in the metric space $\left(X, d^{s}\right)$,

(ii) $(X, d)$ is complete $\Leftrightarrow$ the metric space $\left(X, d^{s}\right)$ is complete. Besides, $\lim _{n \rightarrow \infty} d^{s}\left(x_{n}, x\right)=0 \Leftrightarrow d(x, x)=$ $\lim _{n \rightarrow \infty} d\left(x, x_{n}\right)=\lim _{n, m \rightarrow \infty} d\left(x_{n}, x_{m}\right)$ [16].

Theorem 7. Assume that $(X, d)$ is a complete partial metric space and also suppose that $f: X \rightarrow X$ is a mapping to itself. Then there exists a constant $c \in[0,1)$ providing

$$
d(f x, f y) \leq c d(x, y),
$$

for all $x, y \in X$. So $f$ has an individual fixed point [16].

Recently, Gnana Bhaskar and Lakshmikantham [8] obtained the following nice result for possessing the mixed monotone property mapping, which universalizes Theorem 7 of Matthews [16].

Theorem 8. Suppose that $F: X \times X \rightarrow X$ is a continuous mapping possessing the mixed monotone property on $X$. There exists a $k \in[0,1)$ such that

$$
\begin{array}{r}
d(F(x, y), F(u, v)) \leq \frac{k}{2}[d(x, u)+d(y, v)], \\
\forall x \geq u, y \leq v .
\end{array}
$$

If there exist $x_{0}, y_{0} \in X$ with

$$
x_{0} \leq F\left(x_{0}, y_{0}\right), \quad y_{0} \geq F\left(y_{0}, x_{0}\right),
$$

then, there exist $x, y \in X$ with

$$
x=F(x, y), \quad y=F(y, x) \quad(\text { see }[8,15]) .
$$

The goal of the paper is to build coupled and common fixed point theorems in partially ordered partial metric spaces with a function $\varphi$ providing conditions $\varphi(t)<t$, nonincreasing, and $\lim _{r \rightarrow t^{+}} \varphi(r)<t$ for each $t>0(t)$. Offered theorems universalize and enlarge to a pair of mappings which are conclusions of Gnana Bhaskar and Lakshmikantham [8] and some other theorems related to them.

\section{Main Result}

Definition 9. Assume that $(X, \leq)$ is a partially ordered set and $F, G: X \times X \rightarrow X . F$ and $G$ mappings have the following properties:

$$
\begin{aligned}
& \text { if } n \text { is even, then } F\left(x_{n}, y_{n}\right) \geq G\left(x_{n-1}, y_{n-1}\right) \text { and } \\
& F\left(y_{n}, x_{n}\right) \leq G\left(y_{n-1}, x_{n-1}\right) \text {; } \\
& \text { if } n \text { is odd, then } G\left(x_{n}, y_{n}\right) \geq F\left(x_{n-1}, y_{n-1}\right) \text { and } \\
& G\left(y_{n}, x_{n}\right) \leq F\left(y_{n-1}, x_{n-1}\right) .
\end{aligned}
$$

Theorem 10. Suppose that $(X, \leq)$ is a partially ordered set and $d$ is a partial metric on $X$ with $(X, d)$ being a complete partial metric space. Assume that $F, G: X \times X \rightarrow X$ are satisfied by Definition 2 and also are continuous mappings possessing the mixed monotone property on $X$. Let there be a non-increasing function $\varphi: \mathbb{R}^{+} \rightarrow \mathbb{R}$ such that $\varphi(t)<t$, and $\lim _{r \rightarrow t^{+}} \varphi(r)<t$ for all $t>0$ and also having $x \leq u$ and $y \geq v$, with

$$
\begin{aligned}
& d(F(x, y), G(u, v)) \\
& \quad \leq \varphi\left(\frac{d(x, u)+d(y, v)+d(x, v)+d(y, u)}{2}\right),
\end{aligned}
$$

for $x, y, z, u, v \in X$. If there exists $\left(x_{0}, y_{0}\right) \in X \times X$ with $x_{0} \leq$ $F\left(x_{0}, y_{0}\right)$ and $y_{0} \geq F\left(y_{0}, x_{0}\right)$, at the time $\exists x, y \in X$ with $x=$ $F(x, y)=G(x, y)$ and $y=F(y, x)=G(y, x)$.

Proof. Suppose $x_{0}, y_{0} \in X$ with $x_{0} \leq F\left(x_{0}, y_{0}\right)$ and $y_{0} \geq$ $F\left(y_{0}, x_{0}\right)$. Define sequences $\left\{x_{n}\right\}$ and $\left\{y_{n}\right\}$ in $X$ in the following way:

$$
\begin{array}{cc}
x_{2 n+1}=F\left(x_{2 n}, y_{2 n}\right), & y_{2 n+1}=F\left(y_{2 n}, x_{2 n}\right), \\
x_{2 n+2}=G\left(x_{2 n+1}, y_{2 n+1}\right), & y_{2 n+2}=G\left(y_{2 n+1}, x_{2 n+1}\right) .
\end{array}
$$

We are to prove that $\left\{x_{n}\right\}$ sequence is nondecreasing and $\left\{y_{n}\right\}$ sequence is nonincreasing. That is, for all $n \geq 0$

$$
x_{2 n} \leq x_{2 n+1}, \quad y_{2 n} \geq y_{2 n+1} .
$$

For this, mathematical induction method is used.

Firstly suppose $n=0$. Having $x_{0} \leq x_{1}$ and $y_{0} \geq y_{1}$, because $x_{0} \leq F\left(x_{0}, y_{0}\right)$ and $y_{0} \geq F\left(y_{0}, x_{0}\right)$ and as $x_{1}=$ $F\left(x_{0}, y_{0}\right)$ and $y_{1}=F\left(y_{0}, x_{0}\right)$, so (10) is verified for $n=0$. 
Assume that (10) is satisfied for a constant $n \geq 0$; then, because $x_{2 n} \leq x_{2 n+1}$ and $y_{2 n} \geq y_{2 n+1}$, from Definition 9 we have

$$
\begin{aligned}
& x_{2 n+1}=F\left(x_{2 n}, y_{2 n}\right) \leq G\left(x_{2 n+1}, y_{2 n+1}\right)=x_{2 n+2}, \\
& y_{2 n+1}=F\left(y_{2 n}, x_{2 n}\right) \geq G\left(y_{2 n+1}, y_{2 n+1}\right)=y_{2 n+2} .
\end{aligned}
$$

Thus we get $x_{2 n} \leq x_{2 n+1}$ and $y_{2 n} \geq y_{2 n+1}$.

Hereby, by the induction method we conclude that (10) hold for all $n \geq 0$. Thereof,

$$
\begin{aligned}
& x_{0} \leq x_{1} \leq x_{2} \leq \cdots \leq x_{n} \leq x_{n+1} \leq \cdots, \\
& y_{0} \geq y_{1} \geq y_{2} \geq \cdots \geq y_{n} \geq y_{n+1} \geq \cdots .
\end{aligned}
$$

Denote

$$
\delta_{n}=d\left(x_{n}, x_{n+1}\right)+d\left(y_{n}, y_{n+1}\right),
$$

showing $\left\{\delta_{n}\right\}$ sequence is nonincreasing. From (10) and (8) we have

$$
\begin{aligned}
& d\left(x_{2 n+1}, x_{2 n+2}\right)=d(\left.F\left(x_{2 n}, y_{2 n}\right), G\left(x_{2 n+1}, y_{2 n+1}\right)\right) \\
& \leq \varphi(\left(d\left(x_{2 n}, x_{2 n+1}\right)+d\left(y_{2 n}, y_{2 n+1}\right)\right. \\
&\left.\quad d\left(x_{2 n}, y_{2 n+1}\right)+d\left(y_{2 n}, x_{2 n+1}\right)\right) \\
&\left.\times 2^{-1}\right) \\
& \leq \varphi\left(\frac{d\left(x_{2 n}, x_{2 n+1}\right)+d\left(y_{2 n}, y_{2 n+1}\right)}{2}\right) .
\end{aligned}
$$

Similarly, we can obtain

$$
d\left(y_{2 n+1}, y_{2 n+2}\right) \leq \varphi\left(\frac{d\left(x_{2 n}, x_{2 n+1}\right)+d\left(y_{2 n}, y_{2 n+1}\right)}{2}\right) .
$$

Thus, using properties of $\varphi$ function we get

$$
\begin{aligned}
& d\left(x_{2 n+1}, x_{2 n+2}\right)+d\left(y_{2 n+1}, y_{2 n+2}\right) \\
& \quad \leq 2 \varphi\left(\frac{d\left(x_{2 n}, x_{2 n+1}\right)+d\left(y_{2 n}, y_{2 n+1}\right)}{2}\right) \\
& \quad \leq 2 \frac{d\left(x_{2 n}, x_{2 n+1}\right)+d\left(y_{2 n}, y_{2 n+1}\right)}{2} \\
& \quad=d\left(x_{2 n}, x_{2 n+1}\right)+d\left(y_{2 n}, y_{2 n+1}\right) .
\end{aligned}
$$

Similarly one can show that

$$
\begin{aligned}
& d\left(x_{2 n+2}, x_{2 n+3}\right)+d\left(y_{2 n+2}, y_{2 n+3}\right) \\
& \quad \leq d\left(x_{2 n+1}, x_{2 n+2}\right)+d\left(y_{2 n+1}, y_{2 n+2}\right) .
\end{aligned}
$$

Then, we obtain

$$
\begin{aligned}
& d\left(x_{n+1}, x_{n+2}\right)+d\left(y_{n+1}, y_{n+2}\right) \\
& \quad \leq d\left(x_{n}, x_{n+1}\right)+d\left(y_{n}, y_{n+1}\right) \\
& \quad \leq \cdots \leq d\left(x_{0}, x_{1}\right)+d\left(y_{0}, y_{1}\right) .
\end{aligned}
$$

Thus a sequence $\left\{\delta_{n}\right\}$ is nonincreasing. Thence, there is a $\delta \geq 0$ is obtained with

$$
\lim _{n \rightarrow \infty} \delta_{n}=\delta .
$$

Now, we claim that

$$
\lim _{n \rightarrow \infty} \delta_{n}=0 .
$$

we substitute $n=2 k$ in (14). Then we can get

$$
\begin{aligned}
\delta_{n}=\delta_{2 k}= & d\left(x_{2 k}, x_{2 k+1}\right)+d\left(y_{2 k}, y_{2 k+1}\right) \\
& \leq 2 \varphi\left(\frac{d\left(x_{2 k-1}, x_{2 k}\right)+d\left(y_{2 k-1}, y_{2 k}\right)}{2}\right) \\
& =2 \varphi\left(\frac{\delta_{n-1}}{2}\right) .
\end{aligned}
$$

Letting $n \rightarrow \infty$ in (22), we get

$$
\delta=\lim \delta_{n} \leq 2 \lim \varphi\left(\frac{\delta_{n-1}}{2}\right) \leq 2 \frac{\delta}{2}=\delta .
$$

Hence $\delta=0$. That is

$$
\lim _{n \rightarrow \infty} d\left(y_{n}, y_{n+1}\right)+d\left(x_{n}, x_{n+1}\right)=0 .
$$

Now we show that

$$
\lim _{n \rightarrow \infty} d\left(y_{n}, y_{m}\right)+d\left(x_{n}, x_{m}\right)=0 .
$$

Suppose the contrary. At the time there exists $\varepsilon>0$ when obtaining two subsequences $\left\{x_{2 n(i)}\right\}$ and $\left\{x_{2 m(i)}\right\}$ of $\left\{x_{n}\right\}$ with $2 n(i)$ is the smallest index where

$$
2 n(i)>2 m(i)>i, \quad d\left(x_{2 m(i)}, x_{2 n(i)}\right)+d\left(y_{2 m(i)}, y_{2 n(i)}\right) \geq \varepsilon .
$$

This means that

$$
d\left(x_{2 m(i)}, x_{2 n(i)-1}\right)+d\left(y_{2 m(i)}, y_{2 n(i)-1}\right)<\varepsilon .
$$

By $\left(\mathrm{pms}_{4}\right)$ in Definition 3 and (27), we have

$$
\begin{aligned}
d\left(x_{2 m(i)}, x_{2 n(i)}\right) \leq & d\left(x_{2 m(i)}, x_{2 m(i)+1}\right)+d\left(x_{2 m(i)+1}, x_{2 n(i)}\right) \\
& -d\left(x_{2 m(i)+1}, x_{2 m(i)+1}\right) \\
\leq & d\left(x_{2 m(i)}, x_{2 m(i)+1}\right)+d\left(x_{2 m(i)+1}, x_{2 n(i)}\right) \\
\leq & d\left(x_{2 m(i)}, x_{2 m(i)+1}\right)+d\left(x_{2 m(i)+1}, x_{2 m(i)}\right) \\
& +d\left(x_{2 m(i)}, x_{2 n(i)}\right)-d\left(x_{2 m(i)}, x_{2 m(i)}\right) \\
\leq & 2 d\left(x_{2 m(i)}, x_{2 m(i)+1}\right)+d\left(x_{2 m(i)}, x_{2 n(i)}\right) \\
\leq & 2 d\left(x_{2 m(i)}, x_{2 m(i)+1}\right)+d\left(x_{2 m(i)}, x_{2 n(i)-1}\right) \\
& +d\left(x_{2 n(i)-1}, x_{2 n(i)}\right) .
\end{aligned}
$$


Similarly, we can obtain that

$$
\begin{aligned}
d\left(y_{2 m(i)}, y_{2 n(i)}\right) \leq & 2 d\left(y_{2 m(i)}, y_{2 m(i)+1}\right)+d\left(y_{2 m(i)}, y_{2 n(i)-1}\right) \\
& +d\left(y_{2 n(i)-1}, y_{2 n(i)}\right) .
\end{aligned}
$$

Adding (28) and (29) and also from (27) and (26) we get

$$
\begin{array}{rl}
\varepsilon \leq & d\left(x_{2 m(i)}, x_{2 n(i)}\right)+d\left(y_{2 m(i)}, y_{2 n(i)}\right) \\
\leq 2 & d\left(x_{2 m(i)}, x_{2 m(i)+1}\right) \\
& \left.+d\left(y_{2 m(i)}, y_{2 m(i)+1}\right)\right]+\varepsilon \\
& +d\left(x_{2 n(i)-1}, x_{2 n(i)}\right) \\
+ & d\left(y_{2 n(i)-1}, y_{2 n(i)}\right) .
\end{array}
$$

Taking the limit as $i \rightarrow \infty$ in (30) and by (26) we get

$$
\lim _{i \rightarrow \infty} d\left(x_{2 m(i)}, x_{2 n(i)}\right)+d\left(y_{2 m(i)}, y_{2 n(i)}\right)=\varepsilon .
$$

Employing the triangle inequality,

$$
\begin{aligned}
& d\left(x_{2 m(i)}, x_{2 n(i)}\right)+d\left(y_{2 m(i)}, y_{2 n(i)}\right) \\
& \leq d\left(x_{2 m(i)}, x_{2 n(i)-1}\right)+d\left(y_{2 m(i)}, y_{2 n(i)-1}\right) \\
& \quad+d\left(x_{2 n(i)-1}, x_{2 n(i)}\right) \\
& \quad+d\left(y_{2 n(i)-1}, y_{2 n(i)}\right) .
\end{aligned}
$$

Similarly, we get

$$
\begin{aligned}
& d\left(x_{2 m(i)}, x_{2 n(i)-1}\right)+d\left(y_{2 m(i)}, y_{2 n(i)-1}\right) \\
& \leq d\left(x_{2 m(i)}, x_{2 n(i)}\right)+d\left(y_{2 m(i)}, y_{2 n(i)}\right) \\
& \quad+d\left(x_{2 n(i)}, x_{2 n(i)-1}\right) \\
& \quad+d\left(y_{2 n(i)}, y_{2 n(i)-1}\right) .
\end{aligned}
$$

As $i \rightarrow \infty$ in (33) and (32) and from (31) and (26) we can obtain

$$
\lim _{i \rightarrow \infty} d\left(x_{2 m(i)}, x_{2 n(i)-1}\right)+d\left(y_{2 m(i)}, y_{2 n(i)-1}\right)=\varepsilon .
$$

Since from (12) we have $x_{2 m(i)} \leq x_{2 n(i)-1}$ and $y_{2 m(i)} \geq$ $y_{2 n(i)-1}$ and also by (8) and (10),

$$
\begin{aligned}
& d\left(x_{2 m(i)+1}, x_{2 n(i)}\right) \\
& =d\left(F\left(x_{2 m(i)}, y_{2 m(i)}\right), G\left(x_{2 n(i)-1}, y_{2 n(i)-1}\right)\right) \\
& \leq \varphi\left(\left(d\left(x_{2 m(i)}, x_{2 n(i)-1}\right)\right.\right. \\
& \left.\left.\quad+d\left(y_{2 m(i)}, y_{2 n(i)-1}\right)\right) \times 2^{-1}\right) \\
& <\frac{d\left(x_{2 m(i)}, x_{2 n(i)-1}\right)+d\left(y_{2 m(i)}, y_{2 n(i)-1}\right)}{2} .
\end{aligned}
$$

Similarly, we get

$$
d\left(y_{2 m(i)+1}, y_{2 n(i)}\right)<\frac{d\left(x_{2 m(i)}, x_{2 n(i)-1}\right)+d\left(y_{2 m(i)}, y_{2 n(i)-1}\right)}{2} \text {. }
$$

Thus

$$
\begin{aligned}
& d\left(x_{2 m(i)+1}, x_{2 n(i)}\right)+d\left(y_{2 m(i)+1}, y_{2 n(i)}\right) \\
& <d\left(x_{2 m(i)}, x_{2 n(i)-1}\right) \\
& +d\left(y_{2 m(i)}, y_{2 n(i)-1}\right) .
\end{aligned}
$$

As $i \rightarrow \infty$ in (37) we get $\varepsilon=0$, which is a contrast. Whence (25) is verified, possessing

$$
\lim _{n, m \rightarrow \infty} d\left(x_{n}, x_{m}\right)=0, \quad \lim _{n, m \rightarrow \infty} d\left(y_{n}, y_{m}\right)=0 .
$$

By (3), we have

$$
\begin{aligned}
& d^{s}\left(x_{n}, x_{m}\right) \leq 2 d\left(x_{n}, x_{m}\right)=0, \\
& d^{s}\left(y_{n}, y_{m}\right) \leq 2 d\left(y_{n}, y_{m}\right)=0 .
\end{aligned}
$$

$\left\{x_{n}\right\}$ and $\left\{y_{n}\right\}$ are Cauchy sequences in the metric space $\left(X, d^{s}\right)$. Because $(X, d)$ is complete, it is also the case for $\left(X, d^{s}\right)$, then there exist $a, b \in X$ with

$$
\lim _{n \rightarrow \infty} d^{s}\left(x_{n}, a\right)=0, \quad \lim _{n \rightarrow \infty} d^{s}\left(y_{n}, b\right)=0 .
$$

On the other hand, we have

$$
d^{s}\left(x_{n}, a\right)=2 d\left(x_{n}, a\right)-d\left(x_{n}, x_{n}\right)-d(a, a) .
$$

Getting the limit as $n \rightarrow \infty$ in the upward equation and utilizing (40) and (38), we attain

$$
\lim _{n \rightarrow \infty} d\left(x_{n}, a\right)=\frac{1}{2} d(a, a),
$$

in other words, possessing $d(a, a) \leq d\left(a, x_{n}\right)$ for all $n \in \mathbb{N}$. On letting $n \rightarrow \infty$, we achieve

$$
d(a, a) \leq \lim _{n \rightarrow \infty} d\left(a, x_{n}\right)
$$

Using (42) and (43), we get that

$$
\lim _{n \rightarrow \infty} d\left(a, x_{n}\right)=d(a, a)=0 .
$$

Analogously, one can show that

$$
\lim _{n \rightarrow \infty} d\left(b, y_{n}\right)=d(b, b)=0
$$

exposing $a=F(a, b), a=G(a, b), b=F(b, a)$, and $b=$ $G(b, a)$. To do that we prove the following steps.

Step 1. Demonstrate that $d(F(a, b), F(a, b))=0$ and $d(G(a, b), G(a, b))=0$. 
Since $a \leq a$ and $b \leq b$, we have

$$
\begin{aligned}
& d(F(a, b), F(a, b)) \\
& \leq d\left(F(a, b), x_{2 n+2}\right)+d\left(x_{2 n+2}, F(a, b)\right)-d\left(x_{2 n+2}, x_{2 n+2}\right) \\
& \leq d\left(F(a, b), x_{2 n+2}\right)+d\left(x_{2 n+2}, F(a, b)\right) \\
& =2 d\left(F(a, b), G\left(x_{2 n+1}, x_{2 n+1}\right)\right) \\
& \leq 2 \varphi\left(\frac{d\left(a, x_{2 n+1}\right)+d\left(b, y_{2 n+1}\right)}{2}\right) \\
& \leq d\left(a, x_{2 n+1}\right)+d\left(b, y_{2 n+1}\right) .
\end{aligned}
$$

Letting $n \rightarrow \infty$ in (46) we get $d(F(a, b), F(a, b))=0$. The same one can demonstrate that $d(G(a, b), G(a, b))=0$.

Step 2. We show that $\lim _{n \rightarrow \infty} d\left(x_{2 n+1}, F(a, b)\right)=d(F(a, b)$, $F(a, b))$ and $\lim _{n \rightarrow \infty} d\left(x_{2 n+2}, G(a, b)\right)=d(G(a, b), G(a, b))$.

We have $d\left(x_{2 n+1}, F(a, b)\right)=d\left(F\left(x_{2 n}, y_{2 n}\right), F(a, b)\right)$. Since $x_{n} \rightarrow a$ and $y_{n} \rightarrow b$ as $n \rightarrow \infty$ in $(X, d)$ and $F$ is continuous as $n \rightarrow \infty$ in $(X, d)$, then we get

$$
F\left(x_{2 n}, y_{2 n}\right) \longrightarrow F(a, b)
$$

That is,

$$
\begin{aligned}
\lim _{n \rightarrow \infty} d\left(x_{2 n+1}, F(a, b)\right) & =\lim _{n \rightarrow \infty} d\left(F\left(x_{2 n}, y_{2 n}\right), F(a, b)\right) \\
& =d(F(a, b), F(a, b)) .
\end{aligned}
$$

Similarly one can show that $G\left(x_{2 n+1}, y_{2 n+1}\right) \rightarrow G(a, b)$.

Step 3. Indicating $a=F(a, b)$ and $a=G(a, b)$, we have

$$
\begin{aligned}
d(a, F(a, b)) \leq & d\left(a, x_{2 n+1}\right)+d\left(x_{2 n+1}, F(a, b)\right) \\
& -d\left(x_{2 n+1}, x_{2 n+1}\right) \\
\leq & d\left(a, x_{2 n+1}\right)+d\left(x_{2 n+1}, F(a, b)\right),
\end{aligned}
$$

While $n \rightarrow \infty$ in (49) and employing (46) and Steps 1 and 2, we obtain $d(a, F(a, b))=0$. By $\left(\mathrm{pms}_{1}\right)$ and $\left(\mathrm{pms}_{2}\right)$ in Definition 3 , we have $a=F(a, b)$. Similarly one can show that $a=G(a, b), b=F(b, a)$, and $b=G(b, a)$.

Theorem 11. Intercalarily to the supposition of Theorem 10 assume that there exist $x^{*}, y^{*}$ such that $x^{*}$ is compared with $y^{*}$. Then $x^{*}=y^{*}$ for $\left(x^{*}, y^{*}\right)$ is couple common fixed point. To wit, $F$ and $G$ possess a couple common fixed point and $F\left(x^{*}, x^{*}\right)=x^{*}=G\left(x^{*}, x^{*}\right)$.
Proof. If $x^{*}$ is comparable to $y^{*}$, at the time $F\left(x^{*}, y^{*}\right)=x^{*}$ is comparable to $F\left(y^{*}, x^{*}\right)=y^{*}$. So if we substitute $x=x^{*}$, $y=y^{*}, u=y^{*}$, and $v=x^{*}$ in (8), then we obtain

$$
\begin{aligned}
d\left(x^{*}, y^{*}\right)= & d\left(F\left(x^{*}, y^{*}\right), G\left(x^{*}, y^{*}\right)\right) \\
\leq & \varphi\left(\left(d\left(x^{*}, y^{*}\right)+d\left(y^{*}, x^{*}\right)\right.\right. \\
& \left.\left.\quad+d\left(x^{*}, x^{*}\right)+d\left(y^{*}, y^{*}\right)\right) \times 2^{-1}\right) \\
\leq & \varphi\left(\frac{d\left(x^{*}, y^{*}\right)}{2}\right) \\
< & \frac{d\left(x^{*}, y^{*}\right)}{2} .
\end{aligned}
$$

Therefore $x^{*}=y^{*}$.

\section{Conflict of Interests}

The authors declare that there is no conflict of interests regarding the publication of this paper.

\section{References}

[1] M. Abbas, T. Nazir, and S. Radenović, "Common fixed points of four maps in partially ordered metric spaces," Applied Mathematics Letters, vol. 24, no. 9, pp. 1520-1526, 2011.

[2] A. Alotaibi and S. M. Alsulami, "Coupled fixed and coincidence points for monotone operators in partial ordered metric spaces," Fixed Point Theory and Applications, vol. 2011, article 44, 2011.

[3] S. M. Alsulami, N. Hussain, and A. Alotaibi, "Coupled fixed and coincidence points for monotone operators in partial metric spaces," Fixed Point Theory and Applications, vol. 2012, article 173, 2012.

[4] I. Altun, F. Sola, and H. Simsek, "Generalized contractions on partial metric spaces," Topology and its Applications, vol. 157, no. 18, pp. 2778-2785, 2010.

[5] I. Altun and A. Erduran, "Fixed point theorems for monotone mappings on partial metric spaces," Fixed Point Theory and Applications, Article ID 508730, 10 pages, 2011.

[6] H. Aydi, E. Karapnar, and B. Samet, "Remarks on some recent fixed point theorems," Fixed Point Theory and Applications, vol. 2012, no. 76, 2012.

[7] H. Aydi, "Some coupled fixed point results on partial metric spaces," International Journal of Mathematics and Mathematical Sciences, vol. 2011, Article ID 647091, 11 pages, 2011.

[8] T. Gnana Bhaskar and V. Lakshmikantham, "Fixed point theorems in partially ordered metric spaces and applications," Nonlinear Analysis: Theory, Methods \& Applications, vol. 65, no. 7, pp. 1379-1393, 2006.

[9] F. E. Browder, "On a generalization of the Schauder fixed point theorem," Duke Mathematical Journal, vol. 26, pp. 291-303, 1959.

[10] A. Erduran and M. Imdad, "Coupled fixed point theorems for generalized Meir-Keeler contractions in ordered partial metric spaces," Nonlinear Analysis-theory Methods \& Applications, vol. 2012, Article ID 169, 17 pages, 2012.

[11] V. I. Istrăţescu, Fixed Point Theory an Introduction, vol. 7 of Mathematics and its Applications, D. Reidel, Dordrecht, The Netherlands, 1981. 
[12] E. Karapinar, "Couple fixed point theorems for nonlinear contractions in cone metric spaces," Computers \& Mathematics with Applications, vol. 59, no. 12, pp. 3656-3668, 2010.

[13] E. Karapinar, "Remarks on coupled fixed point theorems in partially ordered metric spaces," Bulletin of Mathematical Analysis and Applications, vol. 4, no. 3, pp. 115-128, 2012.

[14] M. A. Khamsi and W. A. Kirk, An Introduction to Metric Spaces and Fixed Point Theory, JohnWiley \& Sons, New York, NY, USA, 2001.

[15] V. Lakshmikantham and L. Ćirić, "Coupled fixed point theorems for nonlinear contractions in partially ordered metric spaces," Nonlinear Analysis: Theory, Methods \& Applications, vol. 70, no. 12, pp. 4341-4349, 2009.

[16] S. G. Matthews, "Partial metric topology," in Papers on General Topology and Applications, vol. 728 of Annals of the New York Academy of Sciences, pp. 183-197, New York Academy of Sciences, New York, NY, USA, 1994.

[17] A. Mutlu and N. Yolcu, "Fixed point theorems for $\Phi_{p}$ operator in cone Banach spaces," Fixed Point Theory and Applications, vol. 2013, 56, 2013.

[18] S. Oltra and O. Valero, "Banach's fixed point theorem for partial metric spaces," Rendiconti dell'Istituto di Matematica dell'Università di Trieste, vol. 36, no. 1-2, pp. 17-26, 2004.

[19] A. C. M. Ran and M. C. B. Reurings, "A fixed point theorem in partially ordered sets and some applications to matrix equations," Proceedings of the American Mathematical Society, vol. 132, no. 5, pp. 1435-1443, 2004.

[20] B. K. Ray, “On Ćirić's fixed point theorem," Fundamenta Mathematicae, vol. 94, no. 3, pp. 221-229, 1977.

[21] S. Romaguera, "A Kirk type characterization of completeness for partial metric spaces," Fixed Point Theory and Applications, vol. 2010, Article ID 493298, 6 pages, 2010.

[22] B. Samet, M. Rajović, R. Lazović, and R. Stojiljković, "Common fixed-point results for nonlinear contractions in ordered partial metric spaces," Fixed Point Theory and Applications, vol. 2011, article 71, 2011.

[23] W. Shatanawi, B. Samet, and M. Abbas, "Coupled fixed point theorems for mixed monotone mappings in ordered partial metric spaces," Mathematical and Computer Modelling, vol. 55, no. 3-4, pp. 680-687, 2012.

[24] D. R. Smart, Fixed Point Theorems, Cambridge University Press, London, UK, 1974.

[25] O. Valero, "On Banach fixed point theorems for partial metric spaces," Applied General Topology, vol. 6, no. 2, pp. 229-240, 2005. 


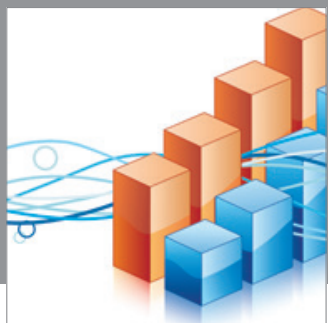

Advances in

Operations Research

mansans

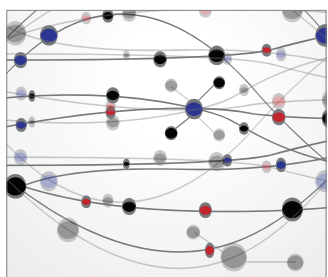

The Scientific World Journal
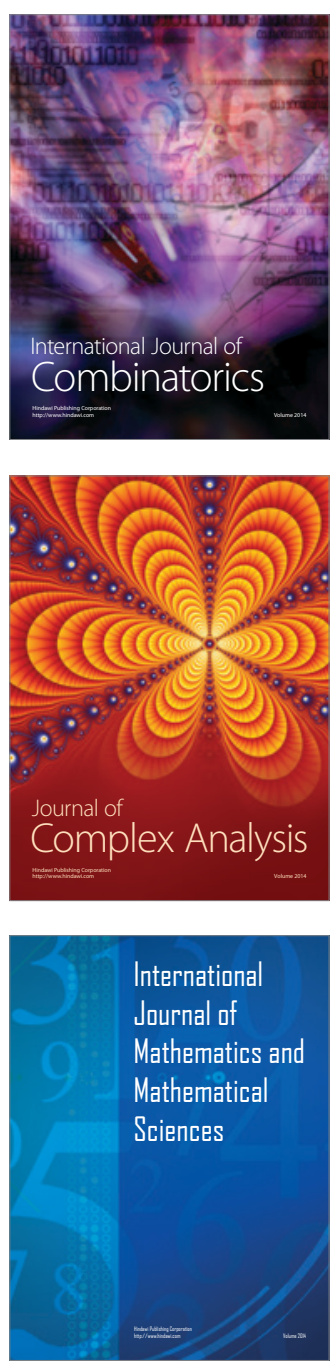
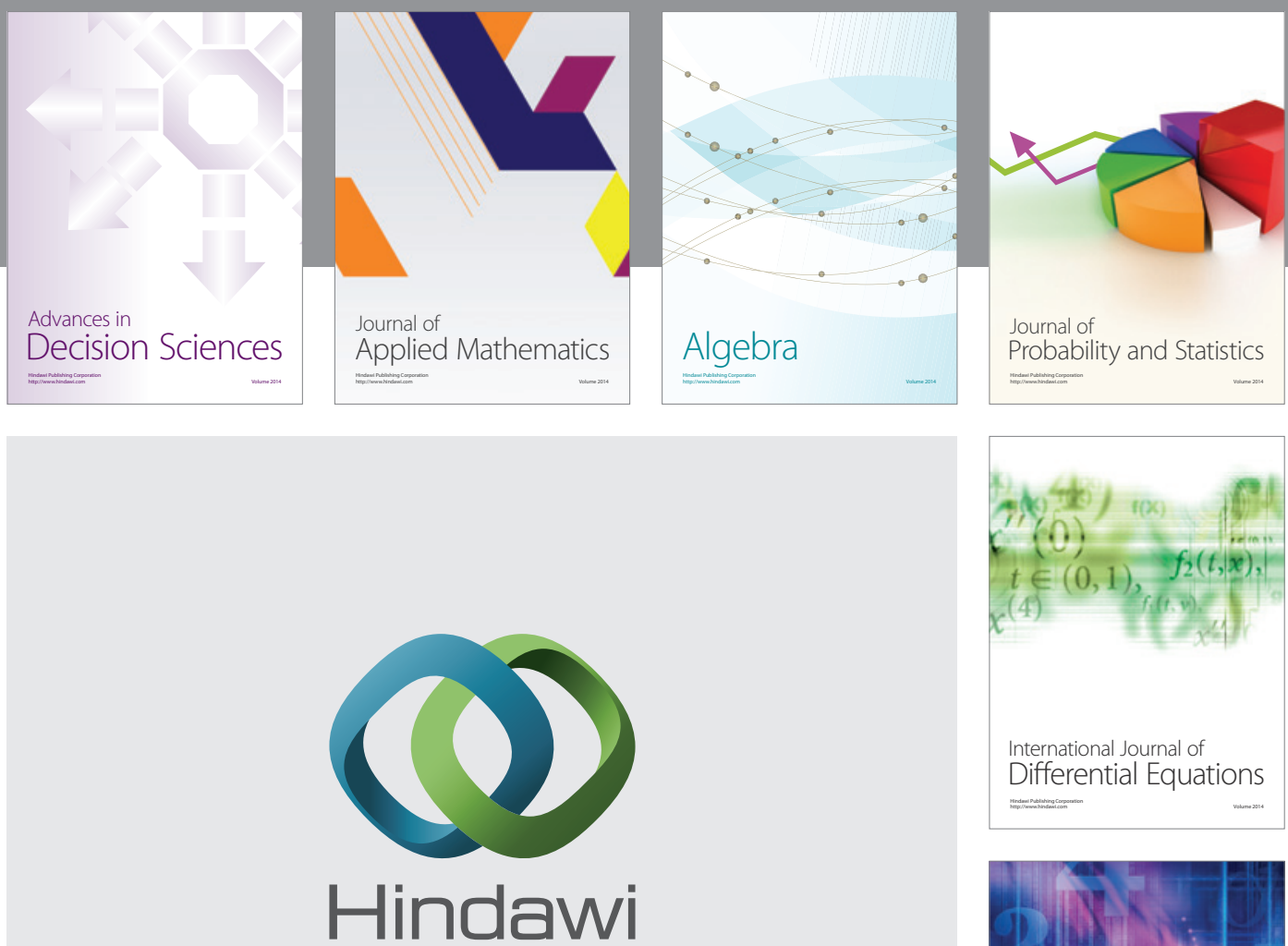

Submit your manuscripts at http://www.hindawi.com
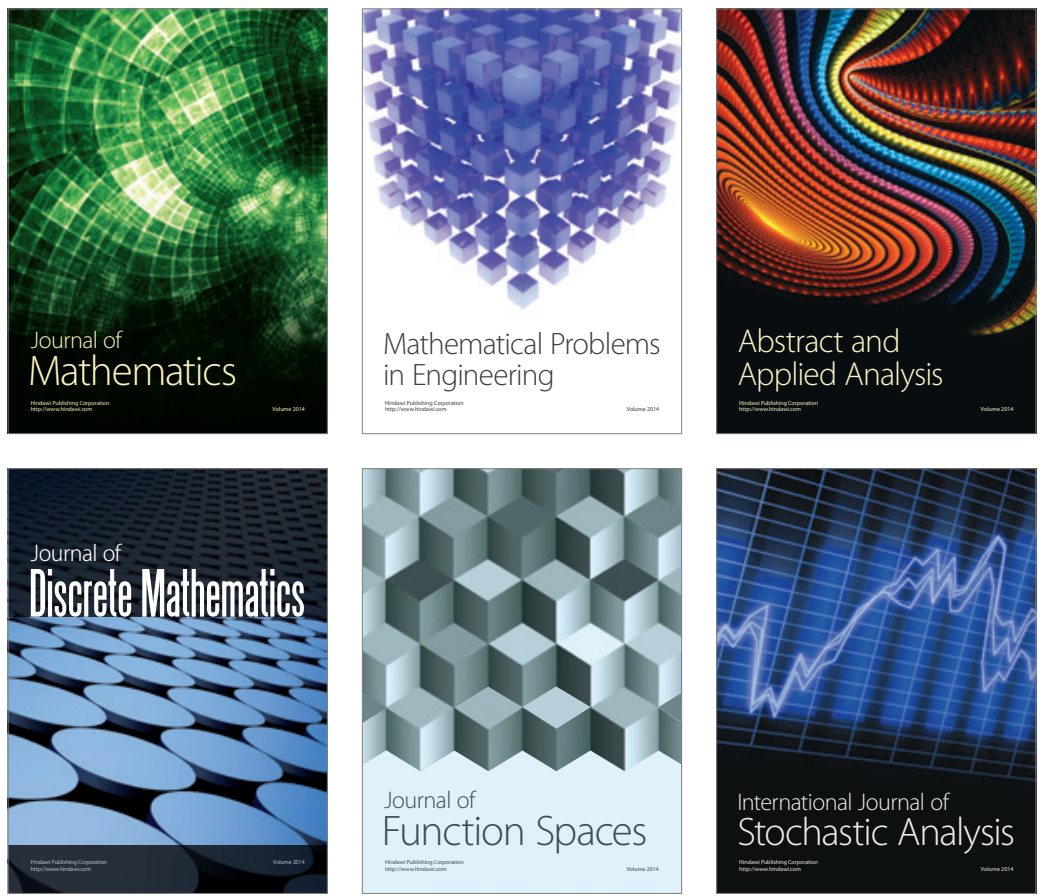

Journal of

Function Spaces

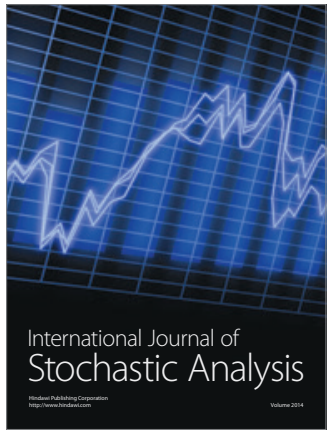

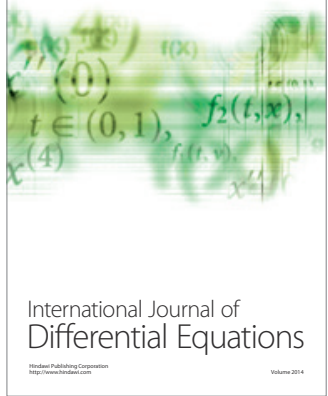
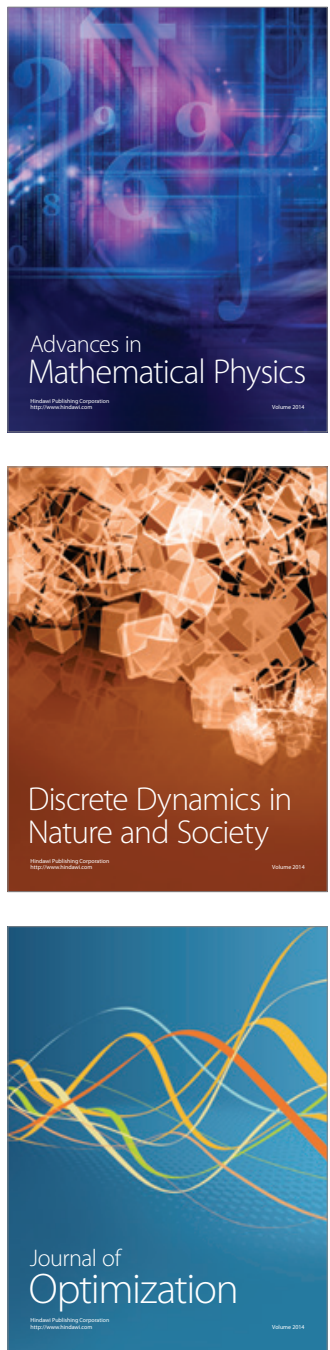